\title{
PENGEMBANGAN LEMBAR KERJA SISWA UNTUK POKOK BAHASAN ASAM BASA BERBASIS BAHAN ALAM MENGGUNAKAN BUAH PUCUK MERAH (Syzygium campanulatum korth)
}

\author{
Sri Haryati, Susilawati, Jumaida \\ Program Studi Pendidikan Kimia FKIP Universitas Riau \\ Email : srifkipunri@yahoo.co.id.
}

\begin{abstract}
Abstrak
Penelitian pengembangan telah dilakukan untuk menghasilkan Lembar Kerja Siswa (LKS) berbasis bahan alam menggunakan buah pucuk merah untuk pokok bahasan asam basa.Penelitian ini termasuk jenis penelitian pengembangan. LKS yang telah dihasilkan divalidasi melalui 3 penilaian yaitu berdasarkan format, isi dan teknis. Hasil rata-rata adalah 3,30 dengan kategori penilaian layak digunakan. Hasil uji coba terbatas di SMA Tribakti dan SMA Taruna Pekanbaru diperoleh nilai rata-rata 3,21 dengan kategori layak. Hasil penilaian guru diperoleh penilaian dengan rata-rata 3,55 dengan kategori layak digunakan. Secara umum LKS yang dihasil layak untuk digunakan pada pelaksanaan praktikum asam basa di SMA.
\end{abstract}

Kata kunci: LKS, bahan alami, buah pucuk merah, asam basa

\begin{abstract}
The study has been conducted to natural produce based Student- Worksheet (SW) using red fruit buds for acid-base topic. This study is classified as the developmental research. The produced worksheet has been validated through 3 assessments criteria : format, content, and technical. The average score is 3.30 which is considered appropiate to use. From the limited try out at SMA Tribakti and SMA Taruna Pekanbaru, the average gained score is 3.21 which is include as appropiate. From the teachers assessment, the average score is 3.55. That is categorized in to appropiate. The produced worksheet is considered appropiate to be used for the lab work for the acid-base topic.
\end{abstract}

Keyword : Student-worksheet, natural produce, and red fruit buds, acid-base

\section{PENDAHULUAN}

Pembelajaran kimia di sekolah dilaksanakan dalam rangka mencapai tujuan pembelajaran. Proses pembelajaran yang dilaksanakan melibatkan proses mental dan fisik siswa baik selama berinteraksi di ruang kelas maupun dalam pelaksanaan praktikum di laboratorium. Penerapan kurikulum 2013, yang mulai diberlakukan tahun ajaran 2013/2014 diamanahkan mengenai salah satu kompetensi inti yang harus dimiliki siswa setelah mempelajari kimia yaitu mampu menerapkan,menganalisis dan mengevaluasi pengetahuan faktual, konseptual, 
prosedural dan metakognitif berdasarkan rasa ingin tahunya tentang ilmu pengetahuan, teknologi, terkait penyebab fenomena dan kejadian serta menerapkan pengetahuan prosedural pada bidang kajian yang spesifik sesuai dengan bakat dan minatnya untuk memecahkan masalah. Kompetensi ini akan dapat dicapai apabila proses pembelajaran di kelas dapat melibatkan siswa secara aktif dan optimal untuk memperoleh pengetahuan. Tuntutan kurikulum ini hendaknya dijabarkan oleh guru dalam bentuk pelaksanaan pembelajaran yang aktif, inovatif kreatif, efektif dan menyenangkan.

Asam Basa merupakan salah satu materi pelajaran kimia yang dipelajari di kelas X dan XI. Observasi telah dilaksanakan tim peneliti pada akhir April 2013 untuk mengetahui pelaksanaan pembelajaran kimia khususnya materi asam basa di beberapa SMA di Pekanbaru tepatnya SMAN 2, SMAN 8, SMAN 11, SMA Tribakti, SMA Taruna. Hasil wawancara dengan beberapa guru kimia yang mengajar di sekolah tersebut dapat dikumpulkan beberapa informasi dan fakta mengenai pelaksanaan praktikum asam basa di sekolah, ternyata semua sekolah (100\%) melaksanakan praktikum asam basa, hanya $40 \%$ (2 SMA)yang menggunakan LKS dalam praktikum, 60\% (3 SMA) tidak menggunakan LKS, hanya menggunakan buku paket. Hasil observasi dari 5 SMA diperoleh fakta bahwa ada 1 SMA (20\%) melaksanakan praktikum menggunakan indikator alami (kunyit, bunga kembang sepatu), sedangkan sekolah yang lain, ( 4 SMA, 80\%) menggunakan indicator universal, dan kertas lakmus. Pelaksanaan praktikum asam basa di sekolah menggunakan LKS yang dimodifikasi guru dari LKS yang dijual oleh penerbit, ternyata tahapan pelaksanaan praktikum hanya mencelupkan kertas indikator universal dan lakmus ke dalam larutan, selanjutnya siswa diminta untuk menjawab pertanyaan yang ada. Guru tidak menyediakan lembar kerja siswa(LKS) sebagai sarana untuk membuat siswa lebih memahami materi pelajaran. Tim peneliti menilai bahwa pelaksanaan praktikum asam basa di sekolah kurang memfasilitasi siswa untuk mendapatkan pengalaman melalui kerja ilmiah dengan media pembelajaran (LKS) yang disediakan.Kondisi ini cukup memprihatinkan, karena siswa seharusnya memperoleh pengalaman belajar yang maksimal di sekolah, difasilitasi dengan sarana dan prasarana yang memadai. 
Tumbuhan pucuk merah sangat banyak digunakan sebagai pohon penghias yang ditanam di halaman rumah dan di jalan-jalan umum. Berdasarkan hasil penelitian Santoni,dkk, 2013 bahwa ekstrak buah pucuk merah (syzygium Campanulatum Korth) dapat dipakai sebagai bahan pewarna alami dengan sifat memberikan warna berbeda dalam suasana asam dan basa. Secara sederhana ekstrak buah pucuk merah dapat diperoleh dengan menggunakan pelarut asam sitrat 3\% . Tidak banyak masyarakat yang mengetahui bahwa tumbuhan pucuk merah memiliki buah. Dengan telah ditemukan zat antosianin dalam ekstrak buah pucuk merah (Santoni, dkk, 2013), maka tim peneliti tertarik untuk memanfaatkannya sebagai indikator alternatif untuk menentukan sifat larutan dalam praktikum asam basa di sekolah.

Lembar kerja siswa (LKS) yang dapat melibatkan siswa secara aktif membuat indikator dari bahan alami buah pucuk merah, belum ditemukan. Tim peneliti tertarik untuk melakukan penelitian pengembangan yang menghasilkan LKS untuk materi asam basa menggunakan buah pucuk merah (syzygium Campanulatum Korth) sebagai indikator alami. LKS yang dihasilkan akan dijadikan sebagai media pembelajaran alternatif dalam melaksanakan pembelajaran kimia untuk materi asam basa di sekolah.

Berdasarkan latar belakang yang diajukan maka penelitian yang dilaksanakan berjudul : Pengembangan Lembar Kerja Siswa Untuk Materi Asam Basa Berbasis Bahan Alam Menggunakan Buah Pucuk merah (syzygium Campanulatum Korth)". Berdasarkan hal tersebut maka penelitian ini bertujuan untuk menghasilkan perangkat pembelajaran dalam bentuk LKS yang layak digunakan pada materi asam basa, serta mengetahui respon guru dan siswa terhadap LKS yang telah dihasilkan.. Hasil penelitian ini daharapkan dapat memberikan kontribusi berupa alternatif LKS yang inovatif dalam pembelajaran asam basa di sekolah dan dapat membantu mahasiswa menyelesaikan tugas akhir dengan menghasilkan 1 skripsi S1.

Lembar kerja siswa (LKS) adalah bagian dari perangkat pembelajaran yang digunakan guru untuk membelajarkan siswa.LKS adalah bagian dari bahan ajar dalam bentuk cetak. LKS berisi informasi perintah guru kepada siswa untuk mengerjakan suatu kegiatan pembelajaran dalam bentuk tugas atau praktikum 
untuk mencapai tujuan pembelajaran. Dalam pembelajaran yang efektif, siswa harus difasilitasi dengan media pembelajaran yang dapat mendukung agar siswa optimal belajar secara fisik dan mental (Wina, 2008).Lembar kerja siswa untuk kegiatan praktikum yang selama ini digunakan seperti buku memasak (cook book).Maksudnya, lembar kerja siswa hanya berisi instruksi kepada siswa untuk mengambil dan mencampurkan zat.Di akhir kegiatan siswa diminta untuk menjawab pertanyaan yang telah disediakan.

LKS praktikum yang ideal adalah LKS yang dapat memfasilitasi siswa untuk memperoleh pengalaman melaksanakan tahapan kerja ilmiah, mulai tahapan persiapan, pelaksanaan dan pelaporan.LKS untuk materi asam basa, sesuai dengan kompetensi dasar yang diambil dari kurikulum mengamanatkan siswa mampu mendeskripsikan teori asam basa dan mampu menentukan sifat larutandan menghitung $\mathrm{pH}$ larutan.LKS yang dimaksud dalam penelitian ini adalah lembar kerja siswa yang dapat melibatkan siswa secara fisik dan mental untuk membuat indikator alami dari buah pucuk merah, dan selanjutnya digunakan untuk menentukan sifat larutan yang belum diketahui. LKS dijadikan sebagai media pembelajaran bagi siswa untuk memperoleh pengalaman membuat indikator dari bahan alam ( buah pucuk merah). Pengalaman yang dimiliki siswa diharapkan dapat menjadikan siswa kreatif dan inovatif, dalam memanfaatkan berbagai bahan alami yang ada di lingkungan sebagai alternatif pengganti indikator buatan dan lakmus. Diharapkan juga siswa memiliki ketertarikan untuk menemukan bahan alami lain sebagai indikator alternatif untuk menentukan sifat larutan.

Pucuk Merah (syzygium campanulatum Korth) merupakan salah satu tumbuhan yang digunakan sebagai tanaman hias (Gambar 1). Tumbuhan ini memiliki buah yang mengandung antosianin. Komponen ini merupakan senyawa flavonoid dari kelompok polifenol, struktur antosianin dapat dilihat pada Gambar 2. Berdasarkan hasil penelitian Santoni, dkk (2013) bahwa buah pucuk merah yang telah diekstraksi menggunakan asam sitrat 3\% mengandung antosianin yang memberikan warna berbeda dalam suasana asam basa dan netral. Menurut Santoni, dkk (2013) antosianin dalam buah pucuk merah stabil pada pH 1-3, sedangkan $\mathrm{pH}$ 4-7, ekstrak antosianin pucuk merah cenderung tidak berwarna. Pada $\mathrm{pH}$ basa menghasilkan warna biru karena bentuk antosianin berubah menjadi 
kuinonoidal. Oleh sebab itu buah pucuk merah memiliki potensi untuk digunakan sebagai indikator yang menunjukkan suatu larutan bersifat asam, basa dan netral.

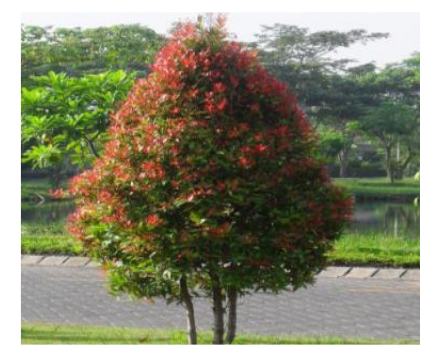

Gambar 1. Tumbuhan pucuk merah (syzygium campanulatum Korth)

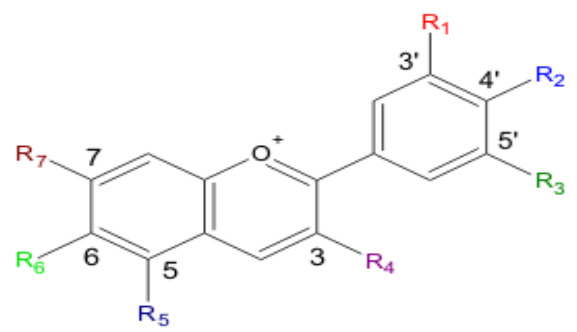

Gambar 2. Struktur antosianin ; sianidin-glikosida dalam buah pucuk merah

(Santoni, dkk 2013)

\section{METODE PENELITIAN}

Jenis penelitian yang dilaksanakan adalah penelitian pengembangan yang menghasilkan produk berupa LKS untuk materi asam basa. Metode penelitian pengembangan menurut langkah-langkah $4 D$-models yang sudah dimodifikasi untuk membuat LKS (Sugiyono, 2009). Langkah-langkah penelitian pengembangan yang disesuaikan untuk pengembangan LKS adalah :

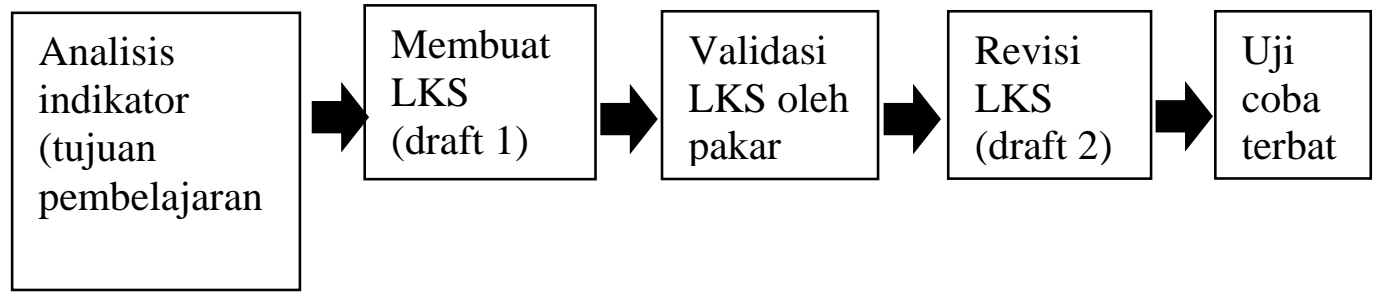

Hasil revisi (draft 2) setelah dari tim pakar, dilanjutkan dengan ujicoba terbatas (uji kelayakan LKS yang telah dibuat). Kegiatan ini melibatkan guru dan 
siswa sebagai pengguna dan penilai.Penelitian ini hanya sampai tahapan uji coba terbatas, mempertimbangkan waktu dan dana yang tersedia.

Teknik pengumpulan data

Produk berupa LKS divalidasi oleh tim pakar (1 orang) menggunakan lembar penilaian dalam bentuk angket. 3 aspek yang dinilai yaitu syarat didaktis, konstruksi dan teknis. Syarat didaktis yaitu syarat yang harus dipenuhi pada saat membuat dan menyusun LKS dengan memperhatikan ketercapaian Standar kompetensi yang telah dijabarkan menjadi indikator dan tujuan pembelajaran (Trianto, 2010). Syarat Konstruksi yaitu berkenaan dengan penggunaan bahasa, susunan kalimat, kosa kata dan kejelasan kata dalam arti susunan kalimat harus mudah dan dapat dimengerti oleh siswa. Syarat teknis yaitu : berkaitan dengan tulisan, gambar dan tampilan LKS.

Uji coba terbatas dengan responden 2 guru kimia dan 20 siswa dari 2 sekolah yang ada di kota Pekanbaru menggunakan angket ditinjau dari aspek kemudahan dalam penggunaan, manfaat yang diperoleh dan efektivitas dalam pembelajaran.

Teknik analisis data

Data yang dikumpulkan diolah secara deskriptif melalui persentasi penilaian tim pakar dan responden (guru dan siswa) berdasarkan kriteria dari skala Likert dengan kriteria kelayakan(r) :

$$
\begin{gathered}
\frac{\bar{X}}{n}=\mathrm{r} \\
\bar{X}=\text { nilai rata }- \text { rata responden }
\end{gathered}
$$

$\mathrm{N}=$ jumlah responden

Skala likert yang digunakan dengan alternatif jawaban: sangat setuju (SS) 4; Setuju (S) 3; tidak setuju (TS) 2; sangat tidak setuju (TST) 1.

Daerah kelayakan:

\begin{tabular}{ll}
\hline Rentang nilai & Kriteria \\
\hline $3,00-4,00$ & Layak \\
\hline $2,00-2,99$ & kurang layak \\
\hline $1,00-1,99$ & tidak layak \\
\hline
\end{tabular}


Jika skor yang diperoleh untuk masing-masing item berada pada range 3,00-4,00 berarti LKS materi asam basa layak digunakan (Arikunto, 2006).

\section{HASIL DAN PEMBAHASAN}

Uji kelayakan dari LKS yang telah dikembangkan ditinjau dari 3 aspek.hasil pengolahan data dapat dilihat pada Tabel 1 .

Tabel 1. Hasil validasi dari pakar

\begin{tabular}{llcc}
\hline No & \multicolumn{1}{c}{ Aspek yang diamati } & $\begin{array}{c}\text { LKS ASAM - } \\
\text { BASA }\end{array}$ & Kategori \\
\hline 1 & Didaktis/isi & 3,00 & \\
\hline 2 & Konstruksi/ Format & 3,50 & \\
\hline 3 & Teknis & 3,40 & \\
\hline & Rata- rata & 3,30 & Layak digunakan \\
\hline
\end{tabular}

Pada Tabel 1. dapat dilihat hasil penilai tim validator, bahwa LKS yang dikembangkan dalam kriteria layak digunakan dengan nilai rata-rata 3,30. Untuk hasil uji coba terbatas, dengan responden guru dan siswa dari 2 sekolah ( SMA Tri

Bakti dan SMA Taruna Pekanbaru), dapat dilihat hasilnya pada Tabel. 2 dan Tabel. 3.

Tabel 2. Hasil Uji Praktikalitas Penggunaan LKS dalam Pembelajaran AsamBasa. (Responden siswa SMA Taruna Pekanbaru)

No Aspek yang diamati Respon Siswa $\quad$ Kriteria

\begin{tabular}{llccl}
\hline & & SMA Tri Bakti & SMA Taruna & \\
\hline 1 & Materi & 3,47 & 3,17 & \\
\hline 2 & Skenario & 3,20 & 3,25 & \\
\hline 3 & Kebahasaan & 3,30 & 3,35 & \\
\hline 4 & Tampilan & 2,95 & 3,00 & \\
\hline & Rata-rata & 3,23 & 3,19 & $\begin{array}{l}3,2,1 \text { baik dan } \\
\text { praktis igunakan }\end{array}$ \\
\hline
\end{tabular}

Tabel 3. Hasil Uji Praktikalitas Penggunaan LKS dalam Pembelajaran AsamBasa. (Responden Guru SMA Taruna dan Tri Bakti Pekanbaru)

\begin{tabular}{llcl}
\hline No & Aspek yang diamati & Respon Guru & Kriteria \\
\hline 1 & Materi & 3,50 & \\
\hline 2 & Skenario & 3,75 & \\
\hline 3 & Kebahasaan & 3,50 & \\
\hline 4 & Tampilan & 3,50 & \\
\hline & Rata-rata & 3,55 & Baik dan praktis digunakan \\
\hline
\end{tabular}


Berdasarkan penelitian yang dilaksanakan telah berhasil dikembangkan media pembelajaran dalam bentuk lembar kerja siswa untuk materi asam basa di kelas X SMA dengan menggunakan indikator alami buah pucuk merah (Syzygium Campanulatum Korth) yang layak digunakan, menurut penilaian tim validator dengan nilai rata-rata 3,30. Ujicoba praktikalitas pada dua sekolah menunjukkan respon siswa dengan nilai rata-rata 3,21 dalam kategori baik. Pada pelaksanaan praktikum dimana siswa terlibat secara aktif menyiapkan indikator alami buah pucuk merah, mulai dari bentuk awal ( buah yang utuh) sampai menjadi filtrat yang siap untuk digunakan dalam menentukan jenis sampel ( asam, basa atau netral). Pengalaman tersebut memberikan tambahan wawasan bagi siswa mengenai alternatif indikator yang berasal dari bahan alami, sesuai dengan Hartono, dalam Portalina dan Titin, 2011) bahwa dengan memberikan pengalaman langsung siswa akan dapat mengembangkan semua potensi dirinya.

Menurut (Santoni,dkk, 2013) ) antosianin yang ada dalam filtrat buah pucuk merah memberikan warna merah dalam suasana asam sampai $\mathrm{pH} 3$ (warna merah tetap stabil), dan warna biru terbentuk dalam suasana basa (sampai pH 9) sehingga buah pucuk merah menjadi salah satu alternatif bahan alami yang dapat dijadikan pengganti indikator universal untuk menentukan jenis suatu larutan sampel.

Pemanfaatan buah pucuk merah sebagai indikator asam basa alternatif dapat pula ditinjau dari kemudahan memperolehnya karena sampai hari ini sangat banyak masyarakat dan pemerintah menjadikan tumbuhan pucuk merah sebagai tanaman hias. Ditinjau dari aspek cara pembuatannya buah pucuk merah cukup mudah dibuat menjadi indikator, cukup dengan menghancurkan buahnya dan ditambahkan air secukupnya, dan disaring, langsung dapat digunaka,(sediaan segar).

\section{KESIMPULAN DAN SARAN}

\section{Kesimpulan}

Berdasarkan hasil dan pembahasan dapat disimpulkan bahwa: 
1. Telah berhasil dikembangkan lembar kerja siswa berbasis bahan alam buah pucuk merah (syzygium Campanulatum Korth) untuk materi asam basa dengan kategori layak digunakan

2. Respon guru dan siswa terhadap LKS yang dikembangkan adalah baik dan praktis digunakan

\section{Saran}

Dari penelitian yang telah dilaksanakan, disarankan agar LKS yang telah dikembangkan dapat dijadikan sebagai salah satu alternatif media pembelajaran yang dapat digunakan dalam pembelajaran asam-basa di sekolah.

\section{Ucapan terima kasih:}

Dalam kesempatan ini, tim peneliti menyampaikan terima kasih kepada pihakpihak yang telah membantu mewujudkan laporan penelitian ini dalam bentuk artikel penelitian diantaranya: Dekan FKIP Universitas Riau yang telah memfasilitasi dana penelitian, Rekan-rekan sejawat, Dosen Prodi Pendidikan Kimia FKIP UR, Guru dan siswa SMA Tri Bakti Pekanbaru, Guru dan siswa SMA Taruna Pekanbaru, Berbagai pihak lain yang telah berpartisipasi

\section{DAFTAR PUSTAKA}

Arikunto, Ss. 2006. Prosedur Penelitian, Rineka Cipta, Jakarta

Dian, W, Sulistyo , S., dan Nanik, D, W. 2015. Pengembangan Media Lembar Kerja Siswa (LKS) Berbasis HierarkiKonsep Untuk Pembelajaran Kimia Kelas XPokok BahasanPereaksi Pembatas. Jurnal Pendidikan Kimia ( JPK). Universitas Sebelas Maret. Vol 4. No.2. Hal 15-22

Dimyati dan Mudjiono, 1999.Belajar dan Pembelajaran. Jakarta

Riduwan dan Sunarto, 2007. Pengantar Statistika Untuk Penelitian. Alfabeta,Bandung

Santoni, A., Djaswir. D., Sukmaning, S. 2013. Isolasi Antosianin dari buah pucuk merah serta pengujian antioksidan dan aplikasi sebagai pewarna alami. Prosiding SEMIRATA FMIPA . Lampung

Sugiyono, 2009, Metode Penelitian Kuantitatif Kualitatif dan $R \& D$, Alfabeta, Bandung.

Slameto, 2003. Belajar dan Faktor - faktor yang mempengaruhinya, Rineka Cipta, Jakarta

Silberman, Melvin L. 2006. Active Learning: 101 cara belajar siswa aktif. Edisi terjemah, cetakan III, Nusa Media,Bandung. 
Trianto, 2010.Mendesain Model Pembalajaran Inovatif-Progresif Konsep, Landasan dan Implementasinya pada Kurikulum Tingkat Satuan Pendidikan (KTSP), Kencana Prenada Media Group, Jakarta.

FKIP, 2013. Buku Panduan Tugas Akhir, FKIP Universitas Riau, Pekanbaru

Tracey, M.W. 2009.Design and Development Research: A model Validation case Educational Technology Research and Development: 57: 553 -571

Wina S, 2008. Strategi Pembelajaran Berorientasi Standar Proses Pendidikan, Kencana Prenada Media Group,Jakarta. 